\title{
Association of skewed X-chromosome inactivation with FMR1 CGG repeat length and anti-Mullerian hormone levels: a cohort study
}

David H. Barad ${ }^{1,2^{*}}$, Sarah Darmon ${ }^{1}$, Andrea Weghofer ${ }^{1,3}$, Gary J. Latham ${ }^{4}$, Filipovic-Sadic ${ }^{4}$, Qi Wang ${ }^{1}$, Vitaly A. Kushnir ${ }^{1,5}$, David F. Albertini ${ }^{1,6}$ and Norbert Gleicher ${ }^{1,2,7}$

\begin{abstract}
Background: Premutation range CGGn repeats of the FMR1 gene denote risk toward primary ovarian insufficiency (POI), also called premature ovarian failure (POF). This prospective cohort study was undertaken to determine if $X$-chromosome inactivation skew $(\mathrm{sXCl})$ is associated with variations in FMR1 CGG repeat length and, if so, is also associated with age adjusted antimüllerian hormone (AMH) levels as an indicator of functional ovarian reserve (FOR).

Methods: DNA samples of 58 women were analyzed for methylation status and confirmation of $C_{G} G_{n}$ repeat length. Based on previously described FMR1 genotypes, there were 18 women with norm FMR1 (both alleles in range of $\mathrm{CGG}_{n=26-34}$ ), and 40 women who had at least one allele at $\mathrm{CGG}_{n<26}$ or $\mathrm{CGG}_{34}$ (not-norm FMR1). As part of a routine evaluation of ovarian reserve, patients at our fertility center have their serum AMH assessed at first visit. Regression models were used to test the association of ovarian reserve, as indicated by serum $\mathrm{AMH}$, with sXCl.

Results: SXCI was significantly lower among infertility patients with norm FMR1 (6.5 \pm 11.1 , median and IQR) compared to those with not-norm FMR1 $(12.0 \pm 14.6, P=0.005)$, though among young oocyte donors the opposite effect was observed. Women age $>30$ to 38 years old demonstrated greater ovarian reserve in the presence of lower $s \mathrm{XCl}$ as evidenced by significantly higher AMH levels (GLM sXCI_10\%, $f=11.27 ; P=0.004)$.

Conclusions: Together these findings suggest that FMR1 CGG repeat length may have a role in determining $X$-chromosome inactivation which could represent a possible mechanism for previously observed association of low age adjusted ovarian reserve with FMR1 variations in repeat length. Further, larger, investigations will be required to test this hypothesis.
\end{abstract}

Keywords: FMR1, Primary Ovarian Insufficiency, Skewed X-chromosome inactivation, AMH, Methylation, Ovarian reserve, POF

\section{Background}

Clinically the FMR1 gene (Xq27.3) is currently primarily associated with the Fragile X syndrome (FXS), characterized by expansion of $\mathrm{CGG}_{\mathrm{n}}$ in the $5^{\prime} \mathrm{UTR}$ region to $\mathrm{CGG}_{\mathrm{n}>200}$. FXS is considered the most common cause of familial mental retardation and autism. Risk screening for FXS is based on FMR1 mutations defined by a normal or common range $\left(\mathrm{CGG}_{\mathrm{n}<45}\right)$, an intermediate or gray zone range between approximately $\mathrm{CGG}_{n=45-54}$ and

\footnotetext{
* Correspondence: dbarad@theCHR.com

'The Center for Human Reproduction (CHR), New York, NY, USA

${ }^{2}$ The Foundation for Reproductive Medicine, New York, NY, USA

Full list of author information is available at the end of the article
}

a premutation range of approximately CGG $n=55-200$. The later can expand within one generation to full mutation length [1].

Tassone et al. reported that full mutation FMR1 carriers demonstrate decreased fragile $\mathrm{X}$ mental retardation protein (FMRP) and increased FMR1 mRNA [2]. The premutation range phenotype has been hypothesized to be the consequence of toxicity of accumulating FMRP protein or FMR1 mRNA transcripts [3-5], and is clinically characterized by significantly increased risk toward POI [6], with a reported prevalence of 16 to $24 \%$ among women in the premutation range [7]. 
Why only a minority of premutation carriers develop POI is unknown. Moreover, over the last decade it has become apparent that more subtle forms of POI, so called occult POI, also appears to be associated with certain $\mathrm{CGG}_{\mathrm{n}}$ ranges, leading to the conclusion that the FMR1 gene in some fashion is associated with speed of follicle loss in ovaries [7]. Others have suggested that, after adjustment for $\mathrm{CGG}_{\mathrm{n}}$, race, smoking, body mass index, and method of ascertainment, additional genes in combination with FMR1 may be responsible for emergence of the POI phenotype [8].

$\mathrm{Fu}$ et al. described the distribution of $\mathrm{CGG}_{n}$ in the normal population to peak around $\mathrm{CGG}_{n=29-30}$ [9]. Based on this observation, we hypothesized that this very large population peak represented a potentially normal $\mathrm{CGG}_{\mathrm{n}}$ range of the FMR1 gene's ovarian function and, indeed, described a normal (norm) range of $\mathrm{CGG}_{n=26-34}$, which allowed for the definition of abnormally low $\mathrm{CGGn}<26^{26}$ and high $\mathrm{CGGn>34}$ mutations. If both $\mathrm{X}$ alleles are in normal range they are considered norm; if one allele is in and the other outside normal range they are considered heterozygous (het), and homozygous (hom) if both alleles are outside normal range. Het and hom mutations were further subdivided based on whether abnormal alleles were high or low [10-12].

In a series of cross sectional studies [10-13] and a longitudinal study [14], we were able to describe associations between these newly defined FMR1 mutations and ovarian aging patterns, leading to the hypothesis that the FMR1 gene affects functional ovarian reserve (FOR) at different ages and, therefore, affects ovarian aging.

The previously noted long known association between premutation range $\mathrm{CGG}_{n}$ and POI in humans [6] also supports an ovarian function of the FMR1 gene, as does a recently reported mouse homologue, which offers further evidence that the gene is involved in ovarian aging [15]. A recently published cross-sectional study of considerable size was, however, unable to find associations between age of natural menopause and number of CGG repeats in traditional normal and intermediate ranges [16].

Though how the FMR1 gene affects ovarian aging remains unknown, we have hypothesized that different mutations in the gene may affect recruitment speed of primordial (or resting) follicles [17]. In drosophila fmr 1 related microRNAs have been associated with primordial germ-line cell suppression and have been described as extrinsic factors for germ-line stem cell maintenance [18]. FMRP has been noted to form a complex with PIWI, a maternal component of the polar granule, a germ-plasm-specific organelle essential for drosophila germline specification [19].

Interestingly, among human FMR1 premutation carriers, POI is dependent upon mutation length, though the relationship is not linear since maximum risk of POI appears to occur among women in $\mathrm{CGG}_{n=80-100}$ range. This is approximately the mid-point of the premutation range of $\mathrm{CGG}_{\mathrm{n} \sim 55-200}$.

Since epigenetic modifications figure prominently in the development of FMR1 syndromes, structural changes in $\mathrm{CGG}_{\mathrm{n}}$ as well as epigenetic effects via methylation and histone modifications can result in transcriptional silencing [20].

$\mathrm{X}$-chromosome inactivation (XCI) in the female achieves dosage compensation with males, and leads to differences in epigenetic markings on the active and inactive X-chromosome [21]. Due to XCI, all females are mosaics with random inactivation of either the maternally or paternally derived X-chromosome [22]. In normal females, $50 \%$ of the $\mathrm{CpG}$ promoter sites of genes subject to XCI are methylated, though they are unmethylated in normal males. Approximately $15 \%$ of genes on the inactive $\mathrm{X}$-chromosome escape inactivation [23]. When XCI is not random, there is an imbalance of cells expressing either the paternal or maternal X-chromosome, known as sXCI [24]. Inactivation of the entire X-chromosome involves many additional specialized factors, histone variants and chromatin modifiers [25].

The present study was undertaken to determine how variations in CGGn repeat length may relate to sXCI, and whether sXCI of the FMR1 gene may be associated with changes in FOR, as assessed by AMH levels.

\section{Methods}

We prospectively assessed 70 reproductive age women, 55 infertility patients (age $36.9 \pm 5.5$ years) presenting to our Center for IVF treatment, and 15 young oocyte donors (age $24.5 \pm 2.4$ ), with a high performance FMR1 PCR and with serum AMH levels. We purposely overrecruited patients with CGG repeats outside our defined normal range of $\mathrm{CGG}_{n=26-34}$. Identical alleles are more common within this normal range and in those individuals sXCI could not be assessed. Censoring those individuals left 58 subjects for the first part of this analysis. We further restricted the study group in a second analysis evaluating ovarian reserve to those subjects without evidence of $\mathrm{AMH}$ above 5 (75th percentile in young women) [26]. This left 50 subjects for that portion of the analysis.

\section{CGG sizing and methylation PCR}

DNA samples were analyzed for methylation status and confirmation of $\mathrm{CGG}_{\mathrm{n}}$ repeat length using AmplideX ${ }^{\circ}$ FMR1 mPCR Reagents (Asuragen, Austin, TX) per the manufacturer's recommended protocol. Briefly, DNA samples were separately aliquoted to a control or methylation-sensitive digestion reaction. Products of the control digestion reaction were amplified using FAMlabeled primers, whereas products of the methylation- 
sensitive reaction were amplified using HEX-labeled primers. The percent methylation for each allele was calculated as the proportion of signal in the HEX- and FAM channels, normalized to reference control signals. The mPCR assay determines both $\mathrm{CGG}_{\mathrm{n}}$ and the methylation status of each allele [27].

Methylation leads to XCI, and is expected to be randomly (50:50) distributed between each X chromosome. Results using the mPCR assay were normally distributed ( $P>0.05$, Shapiro-Wilk test with Benjamin-Hochberg correction) [28], and repeated measurements demonstrated low variance (Table 1) with at least $95 \%$ of the average of all possible pairwise combinations of technical replicates falling within $5 \%$ of the mean methylation value for FMR1 alleles that best represented random $\mathrm{XCI}$. Thus, all study samples were run in replicate using MPCR, and the mean values were used for statistical analyses. In this analysis, the $\mathrm{X}$ chromosome with the lower $\mathrm{CGG}_{\mathrm{n}}$ allele is defined as "X1" and the one with the higher $C G_{n}$ as allele " $X 2$ ". The extent to which the actual observed distribution deviates from 50:50 is measured as the mean skew of X-chromosome inactivation (sXCI). sXCI is, thus, calculated as [ABS (50 - observed percent methylation of X1) + ABS (50 - observed percent methylation of $X 2$ )]/2. When both alleles were identical, the sXCI could not be calculated since we could not identify methylation of the individual FMR1 alleles. sXCI was not normally distributed. We compared quantitative values of sXCI with the Mann-Whitney $U$ test and created a categorical variable for sXCI with cut-off at $10 \%$ skew, the minimum skew that can be supported within the known technical variance of the MPCR assay.

A primary goal of this analysis was to compare the methylation patterns relative to previously defined FMR1 genotypes [12]. We, thus, set out to recruit women from our existing patient pool with norm FMR1 $\left(\mathrm{CGG}_{n=26-34}\right)$ and with at least one $\mathrm{CGG}_{\mathrm{n}<26}$ or $\mathrm{CGG}_{\mathrm{n}>34}$, (not-norm). Proportions of norm and not-norm

Table 1 Variance of mPCR measurements over a range of 1-86\% methylation

\begin{tabular}{lll}
\hline CGG\# & Average $\%$ Methylation $(n=14)$ & Std Dev \\
\hline 18 & $3 \%$ & $1 \%$ \\
30 & $59 \%$ & $4 \%$ \\
32 & $5 \%$ & $1 \%$ \\
56 & $38 \%$ & $4 \%$ \\
85 & $1 \%$ & $1 \%$ \\
116 & $86 \%$ & $11 \%$ \\
$>200$ & $2 \%$ & $1 \%$
\end{tabular}

Values near 50\% methylation (38-59\%) demonstrated standard deviations of $4 \%$ FMR1 alleles representing 7 distinct expansion lengths were assessed in 14 independent MPCR runs using multiple operators to establish the technical variation of the assay study subjects, therefore, are not expected to reflect previously reported percentages in normal populations [29]. Women with known sex chromosome aneuploidy were excluded from the study.

\section{$\mathrm{AMH}$}

The second goal of this study was to examine the possible association between sXCI and FOR, using $\mathrm{AMH}$ as an indicator of FOR. We excluded from this part of the analysis participants with known causes of extreme changes in FOR, such as polycystic ovary syndrome, or with known low FOR (LFOR), such as ovarian dysgenesis, previous oophorectomy, chemotherapy or advanced ovarian age.

As part of a routine evaluation of ovarian reserve, patients at our fertility center have their serum AMH assessed at first visit. AMH was assayed by a single commercial laboratory (Esoterix, Calabasas Hills, California) using an enzymatically amplified two-site immunoassay AMH Gen II ELISA ref A73818, (Beckman Coulter Brea, CA). For women, whose AMH levels were undetectable, the AMH level was set to $0.15 \mathrm{ng} / \mathrm{mL}$ the lowest detectable level with this assay system.

Since AMH is right skewed, to approach normality, we utilized the natural logarithm of AMH in applied regression models. Since AMH is known to vary with age $[26,30]$, all models were also adjusted for age.

Regression models tested included a general linear model (GLM), adjusted for age, in which we created a categorical variable sXCI_10\% for less than or equal to $10 \%$ skew or greater than $10 \%$ skew, the minimum skew that can be supported within the known technical variance of the mPCR assay, (Table 1), to determine how AMH varied in presence of greater or lesser sXCI. To test for interaction with age we created a categorical variable grouping subjects in three age groups with cut-off at 30 and at 38 years old. We focused on the 30 to 38 year old group since this is the time in a woman's reproductive life of rapid change in ovarian reserve and we were interested in the effect of sXCI during that transitional time.

The GLM models tested were:

Ln $(\mathrm{AMH})=\beta 0+\beta 1$ sXCI $10 \%+\beta 2$ Age group $+\beta 3$ sXCI_10\% $\times$ Age group + random error

$\operatorname{Ln}(\mathrm{AMH})=\beta 0+\beta 1$ sXCI $10 \%+\beta 2$ Age + random error

We also ran a Mann-Whitney $U$ test within the three age groups to confirm these findings.

\section{Data}

The datasets during and/or analyzed during the current study available from the corresponding author on reasonable request.

\section{Statistics}

Normality was tested by Kolmogorov-Smirnov test. Quantitative variables were presented as mean \pm standard deviation 
(SD) or geometric mean and 95\% confidence intervals, and qualitative variables as number (\%). Normally distributed variables were compared by GLM ANOVA. The Mann-Whitney $U$ test was used to analyze non-normal quantitative variables and results presented as median $(\mathrm{IQR}=$ interquartile range). All statistical analyses were carried out with the use of the Statistical Package for the Social Sciences 21.0 (IBM SPSS). $P<0.05$ was considered statistically significant.

\section{Results}

A total of 70 women were initially recruited for this study. Excluding those with identical FMR1 alleles left 58 subjects; 46 infertility patients, 12 with norm FMR1 (both alleles at $\mathrm{CGG}_{n=26-34}$ ) and 34 with at least one allele at $\mathrm{CGG}_{\mathrm{n}<26}$ or $\mathrm{CGG}_{>34}$ (not-norm FMR1), and 12 donors, 6 norm and 6 not-norm.

The data were further restricted in the analysis of effects of sXCI on ovarian reserve. Four infertility patients and 4 egg donors with $\mathrm{AMH}$ greater than $5 \mathrm{ng} / \mathrm{mL}$ [31], who were thought to have polycystic ovaries, were also censored which left 50 women of reproductive age as study population for the second portion of the analysis.

Table 2 summarizes the characteristics among the infertility patients and young egg donors in this analysis. As expected, donors were younger and had higher AMH compared to infertility patients. Not surprisingly, donors recruited into this analysis had a higher percentage of normal $\mathrm{CGG}_{n}$ genotypes. However, this dataset was based on intended over recruiting of women outside $\mathrm{CGG}_{n=26-34}$, and does not reflect the natural distribution

Table 2 Characteristics among the infertility patients and young egg donors in this analysis

\begin{tabular}{llll}
\hline & $\begin{array}{l}\text { Infertility Patients } \\
(n=46)\end{array}$ & $\begin{array}{l}\text { Donors } \\
(n=12)\end{array}$ & $P$ \\
\hline Age (years) & $36.5 \pm 5.2$ & $24.7 \pm 2.4$ & $<0.001$ \\
AMH ng/mL ${ }^{a}$ & $0.3(2.0)$ & $4.4(5.1)$ & $<0.001$ \\
CGG_X1 & $29(7)$ & $29(7)$ & 0.745 \\
CGG2_X2 & $31.5(6)$ & $31.5(4)$ & 0.484 \\
CGG & & & \\
$\quad$ Norm & $12(26.1 \%)$ & $6((50.0 \%)$ & - \\
$\quad$ Any Low & $18(39.1 \%)$ & $4(33.3 \%)$ & - \\
$\quad$ Any High & $14(30.4 \%)$ & $2(16.7 \%)$ & - \\
$\quad$ Low/High & $2(4.3 \%)$ & $0(0 \%)$ & - \\
Methylation\%_X1 & $48.7 \pm 17.4$ & $50.7 \pm 19.4$ & 0.740 \\
Methylation\%_X2 & $50.5 \pm 20.6$ & $49.8 \pm 19.3$ & 0.834 \\
Median sXCI ${ }^{a}$ (All) & $10.0(11.0)$ & $11.5(11.5)$ & 0.824 \\
$\quad$ Norm CGG 26 - 34 & $6.5(11.1)(n=12)$ & $19.8(7.9)(n=6)$ & 0.003 \\
Not-Norm CGG <26 & $12.0(14.6)(n=34)$ & $9.3(9.4)(n=6)$ & 0.127 \\
Or CGG $>34$ & & & \\
\hline a Median (IQR); Mann Whitney U test & &
\end{tabular}

of CGG repeats in the general population. sXCI was noted to be significantly higher among donors with $\mathrm{CGG}_{n=26-34}$ compared to infertility patients with norm $\left(\mathrm{CGG}_{n=26-34}\right)(P=0.022)$, though there was no significant difference of sXCI between the infertility patients and donors in the not-norm $\left(\mathrm{CGG}_{\mathrm{n}<26}\right.$ or $\left.\mathrm{CGG}_{\mathrm{n}>34}\right)$ category.

\section{sXCl and $\mathrm{CGG}_{\mathrm{n}}$}

Results for sXCI were significantly different between infertility patients and egg donors. Using the MannWhitney $U$ test sXCI was significantly lower among 12 infertility patients with norm $\left(\mathrm{CGG}_{n=26-34}\right)$ compared to 34 others with not-norm CGG (at least one $C G_{n<26}$ or $\left.\mathrm{CGG}_{\mathrm{n}>34}\right)(\mathrm{Z}=-2.80, P=0.005)$ (Fig. 1). While among egg donors the sXCI was higher among 6 norm women compared to 6 CGG not-norm women $(\mathrm{z}=-2.69, P=$ 0.026 ), though not significantly so when adjusted for multiple comparison.

\section{Ovarian reserve}

Median AMH in the whole study population was $0.935 \mathrm{ng} / \mathrm{mL}$, with range from undetectable $(<0.15 \mathrm{ng} / \mathrm{mL})$ to $13 \mathrm{ng} / \mathrm{mL}$. AMH decreased with age of women, consistent with widely reported findings in the literature $[26,30]$. Median AMH among the 50 women in the AMH restricted study population was $0.35 \mathrm{ng} / \mathrm{mL}$, with range from undetectable $(<0.15 \mathrm{ng} / \mathrm{mL})$ to $4.5 \mathrm{ng} / \mathrm{mL}$.

\section{$\mathrm{SXCl}$ and ovarian reserve}

sXCI was compared in relationship to AMH in 50 women (42 infertility patients and 8 oocyte donors) who demonstrated $\mathrm{AMH}$ levels $\leq 5.0 \mathrm{ng} / \mathrm{mL}$. In a GLM analysis of the effect of Age and sXCI on $\ln \mathrm{AMH}$ we noted a significant interaction between Age and sXCI $(p=0.004)$. Accordingly we analyzed the three age subgroups individually and found that there was a highly significant effect of sXCI on mean AMH among the 16 women who were $>30$ to 38 years old: $\mathrm{sXCI}>10 \%$, AMH $0.2,95 \%$ CI 0.118 to 0.340 and $\mathrm{sXCI} \leq 10 \%$, AMH 1.74 , 95\% CI 0.67 to 2.83 (F11.53, $p=0.004$ ), while there was no observable effect of sXCI among the 15 women $\leq 30$ years old $(\mathrm{F}=1.06, p=0.32)$ or the 19 women $>38$ years old $(\mathrm{F}=3.35, p=0.085) \quad$ (Fig. 2). The Mann-Whitney $U$ test yielded similar findings.

\section{Discussion}

In this study, we report the association of $\mathrm{CGG}_{\mathrm{n}}$ with sXCI, and association of variations in observed sXCI with variations in serum $\mathrm{AMH}$, an important marker of FOR. Combined, the findings, therefore, provide a possible mechanism to explain previously observed associations of the FMR1 gene with variations in FOR. 


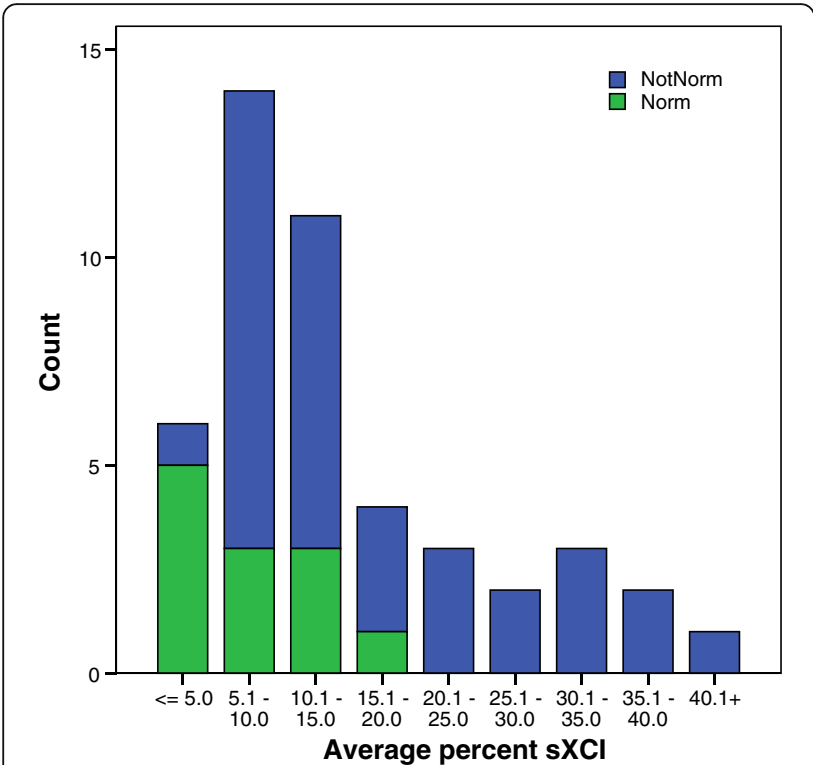

Fig. 1 Distribution of $s \mathrm{XCl}$ among 46 infertility patients categorized by FMR1 repeat status. $\mathrm{SXCl}$ was significantly lower among 12 infertility patients with norm ( $\left.\mathrm{CGG}_{n=26-34}\right)$ compared to 34 others with not-norm CGG (at least one $\mathrm{CGG}_{n<26}$ or $\left.\mathrm{CGG}_{n>34}\right)(Z=-2.80, P=0.005)$

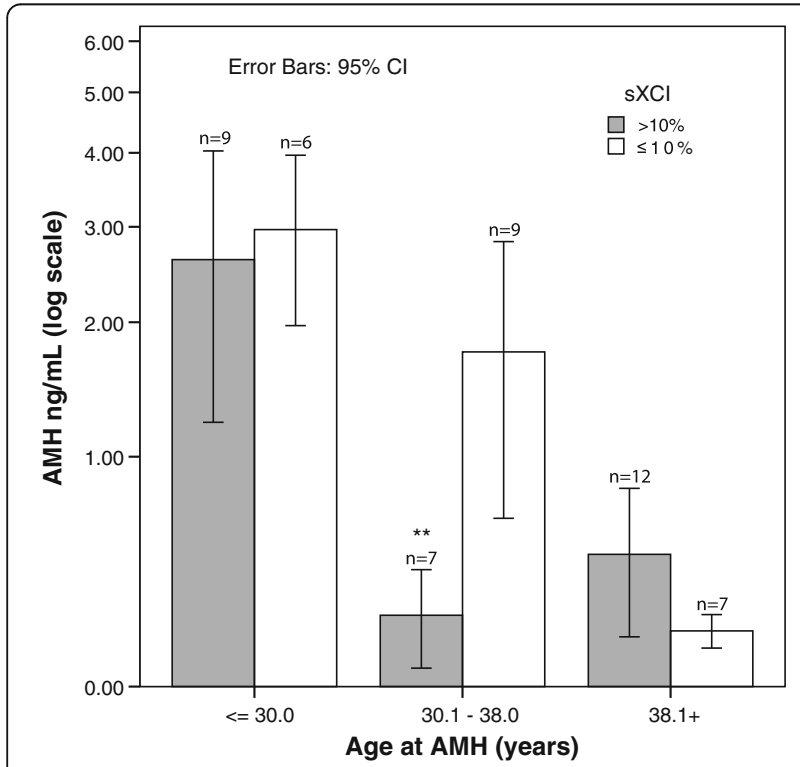

Fig. 2 Bar graph of $\mathrm{AMH}$ against Age categorized by $\mathrm{s} X \mathrm{Cl}$ of $10 \%$. Bar graph of geometric mean and $95 \%$ confidence intervals of $\mathrm{AMH}$ (natural log scale) in three age strata with cut-off at age 30 and 38 years comparing participants in each stratum with $\leq 10 \% \mathrm{sXCl}$ to those with $>10 \% \mathrm{sXCl}$. In a GLM analysis stratified by age-groups there was a significant interaction between $\mathrm{SXCl}$ and age group $(p=0.004)$. While there is no significant difference in AMH observed for women $<30$ or for women $>38$ years old there is a significant difference in the AMH levels for those age $>30$ to $38(n=16)$. In this age group those with $\leq 10 \% \mathrm{sXCl}(n=7)$ demonstrated a significantly higher $\mathrm{AMH}$ level compared to those with > 10\% sXCI $(n=9)$ (GLM sXCI_10\%, $f=11.27 ; P=0.004)$
Among women with $F M R 1$ premutation range $\mathrm{CGG}_{\mathrm{n}}$, alterations in mRNA production have been suggested as a possible cause of premature ovarian failure, while no such abnormalities of mRNA production have been described for women with what is widely considered the common (i.e., normal) range of $\mathrm{CGG}_{\mathrm{n}<55}$.

In the present study, we found that, as $\mathrm{CGG}_{\mathrm{n}}$ deviates from $\mathrm{CGG}_{n=26-34}$ up or down, sXCI will increase. The observation that $\mathrm{CGG}_{\mathrm{n}}$ on both sides of $\mathrm{CGG}_{n=30}$ appears related to methylation skew offers an interesting new possibility of how $\mathrm{CGG}_{\mathrm{n}}$, within the currently considered common (normal) range, may affect FMR1 function. These findings also support our prior clinical reports in which we found increased likelihood of LFOR in infertile women with increasing distance in both directions from $\mathrm{CGG}_{n=29-31}[10,14,17,32]$.

The major effector of $\mathrm{X}$ inactivation is an RNA gene known as Xist (X-inactive specific transcript) [21]. Untranslated RNA transcribed from the Xist gene coats the inactive $\mathrm{X}$ chromosome, leading to its silencing [33, 34]. $\mathrm{X}$ inactivation occurs very early in embryo development, around the time of implantation [35].

Since evidence presented here suggests that $\mathrm{CGG}_{\mathrm{n}}$ of the FMR1 gene appears associated with sXCI, how the $F M R 1$ gene's $\mathrm{CGG}_{\mathrm{n}}$ might affect initiation of Xist inactivation of one $\mathrm{X}$ chromosome raises further interesting questions. Interaction with Xist has previously also been reported for the $B R C A 1$ gene, ${ }^{31,32}$ in itself an interesting finding, as we [36] and others [37] reported distinct $\mathrm{CGG}_{\mathrm{n}}$ distribution patterns in the FMR1 gene in $B R C A$ mutation carriers.

Skewing in favor of larger proportions of normally active $\mathrm{X}$ chromosomes has been previously noted in women with full mutations $[27,38]$ and premutation carrier females [39]. In contrast we are here describing such a pattern in the FMR1 gene with fewer than 55 CGG repeats $\left(\mathrm{CGG}_{\mathrm{n}<55}\right)$.

In this analysis, the overall median skew was $12 \%$. Most investigators consider the threshold for highly skewed X-chromosome inactivation to lie at 80 to $90 \%$ [40]. Others have reported that among 220 unaffected normal females the mean distribution of X-chromosome inactivation was 50:50. Only 9.5\% were considered highly skewed with a threshold of 90 , and $23.6 \%$ with a threshold of $80 \%$ [41].

These numbers raise question about the clinical significance of our observed variations in sXCI since these differences cannot be considered highly skewed.

Observations may, however, be age dependent: In leucocytes of adult females, the full fragile $\mathrm{X}$ mutation was found more often on the inactive $\mathrm{X}$ chromosome, but less so in younger females [42]. We observed an opposite relationship between $\mathrm{sXCI}$ and $\mathrm{CGG}_{\mathrm{n}}$ among young oocyte donors compared to older infertility 
patients. Our analysis noted differences between young oocyte donors and older infertile patients in the significantly higher percentage of sXCI in women with FMR1 alleles outside normal range (i.e., $\mathrm{CGG}_{\mathrm{n}<26}$ or $\mathrm{CGG}_{\mathrm{n}>34}$ ) than in norm range $\left(\mathrm{CGG}_{n=26-34}\right)$. Among older infertility patients, we observed increased sXCI in women with $\mathrm{CGG}_{\mathrm{n}}$ outside norm range, while younger donors did not demonstrate sXCI differences between norm and notnorm women. The importance of $\mathrm{CGG}_{\mathrm{n}}$ for sXCI may, therefore, increase with advancing female age.

We find further evidence of age dependence in that the effects of sXCI were only significant within the $>30$ to 38-year age group of women (Fig. 2). This is, of course, the age in which ovarian reserve first begins to decline and when genetic and environmental effects on ovarian reserve may first become apparent. Among younger women there is sufficient redundancy of functional ovarian reserve to mask these effects while among older women there is generally universal decline. Thus, it is during the transitional time in the 30's when subtle effects on ovarian reserve may be most apparent.

One limitation of this analysis is that this is a relatively small study group mostly comprised of infertility patients with prior evidence of low functional ovarian reserve. Our findings in a small group of healthy egg donors were quite different from those observed in the infertility patients. Thus, these findings may not be generalizable to all women.

Our observation, that a higher sXCI is associated with lower AMH levels, offers a potential insight concerning how deviations from norm $\mathrm{CGG}_{n=26-34}$ may affect FOR.

For technical reasons, such conclusions have, however, to be viewed with a degree of caution: FMR1 genotyping was performed in this study from peripheral blood. Tissue-specific differences in $C_{G} G_{n}$ have been reported in fragile $X$ affected men and women [43], and mosaicism of $\mathrm{CGG}_{\mathrm{n}}$ and methylation is well established [44]. Observations made in peripheral blood, at least theoretically, may, therefore, not reflect the genetic and epigenetic make-up of ovaries.

One can also hypothesize that skewed $\mathrm{X}$ inactivation might influence early gametogenesis, leading later in life to differences in FOR. However others have found that in women with premutation range $\mathrm{CGG}_{\mathrm{n}}$, POI was not associated with increased skewing [41, 45]. Within the traditionally normal range of $\mathrm{CGG}_{\mathrm{n}}<55$, sXCI may, however, indeed be associated with such changes.

\section{Conclusions}

In summary, we report the association of increased lowlevel sXCI of the FMR1 gene with deviations from norm $\mathrm{CGG}_{\mathrm{n}}\left(\mathrm{CGG}_{n=26-34)}\right.$. This association was primarily observed in older infertility patients but not in younger oocyte donors. Among infertility patients of mid- reproductive age, we observed that sXCI greater than $10 \%$ was associated with lower levels of age-adjusted $\mathrm{AMH}$. Together, these observations support previously reported effects of $F M R 1$ genotypes and sub-genotypes on FOR [32, 46], warranting further explorations of the FMR1 gene in reference to FOR at various ages.

\section{Abbreviations}

AMH: Antimüllerian hormone; CGGn: Number of cytosine guanine guanine repeats; FMR1: Fragile X Mental Retardation 1 gene; FMRP: Fragile X mental retardation protein; FOR: Functional ovarian reserve; FXS: Fragile X syndrome; PCR: Polymerase chain reaction; POF: Premature ovarian failure; POI: Premature ovarian insufficiency; sXCl: X-chromosome inactivation skew; XCl: X-chromosome inactivation

\section{Acknowledgements}

The authors gratefully acknowledge the editorial and administrative assistance of the CHR staff without whom this work could not have been completed. We especially recognize the assistance of Ms. Yu Kizawa, of our editorial office, and our administrator Ms. Jolanta Tapper.

\section{Funding}

This study was funded by intramural funds from The Center for Human Reproduction, grants from The Foundation for Reproductive Medicine, a not-for-profit research foundation, and through internal funding at Asuragen.

Availability of data and materials

The datasets during and/or analyzed during the current study available from the corresponding author on reasonable request.

\section{Author contributions \\ Study concept: DHB, GJ, NG; Study design: DHB, AW, VAK, NG; Execution of study - clinical: DHB, VAK, NG; Execution of study - laboratory: Y-GW, QW, DFA, Execution of FMR1 and methylation assays: GJL, S-F S; Statistical ana- Iyses: DHB, SD, GJL; Interpretation of data: DHB, GJL, NG; First manuscript draft DHB, NG; Substantial contributions to subsequent revisions: DHB, AW, GJL, VAK, DFA, NG All authors approved of the final manuscript.}

\section{Competing interests}

$\mathrm{NG}$, and DHB, are co-inventors on several U.S. patents claiming therapeutic benefits from androgen supplementation in women with low functional ovarian reserve (LFOR) and diagnostic benefits from determinations of CGGn on the FMR1 gene in women with low functional ovarian reserve. Both receive royalties from Fertility Nutraceuticals, LLC, in which NG also holds shares. DHB, AW, DFA, VAK, DFA and NG received research support, travel funding and lecture fees from various Pharma and medical device companies in the past, none, however, in any way related to here reported manuscript. GJL and S-FS are employees of Asuragen, a company which markets the proprietary FMR1 methylation reagents used in this study, and GJL is an inventor or co-inventor on U.S. patents related to this technology. All other authors report no potential conflicts with here reported manuscript.

\section{Consent for publication}

Not Applicable. No individual person's data is included in this manuscript in any form.

\section{Ethics approval and consent to participate}

The Institutional Review Board of the Center for Human Reproduction (\#ER2011/12-5/Sub 2) approved this study. All participants consented to having their peripheral blood analyzed for FMR1 and $\mathrm{AMH}$, and, in addition, signed a special informed consent for genetic testing.

\section{Publisher's Note}

Springer Nature remains neutral with regard to jurisdictional claims in published maps and institutional affiliations.

\section{Author details}

${ }^{1}$ The Center for Human Reproduction (CHR), New York, NY, USA. ${ }^{2}$ The

Foundation for Reproductive Medicine, New York, NY, USA. ${ }^{3}$ Department of 
Obstetrics and Gynecology, Vienna University School of Medicine, Vienna, Austria. ${ }^{4}$ Asuragen, Austin, TX, USA. ${ }^{5}$ Department of Obstetrics and Gynecology, Wake Forest University, Winston Salem, NC, USA. ${ }^{6}$ Department of Molecular and Integrative Physiology, University of Kansas Medical Center, Kansas, USA. ${ }^{7}$ Stem Cell and Molecular Embryology Laboratory, The Rockefeller University, New York, NY, USA.

\section{Received: 31 December 2016 Accepted: 19 April 2017} Published online: 28 April 2017

\section{References}

1. Willemsen R, Levenga J, Oostra BA. CGG repeat in the FMR1 gene: size matters. Clin Genet. 2011;80:214-25.

2. Tassone F, Hagerman RJ, Chamberlain WD, Hagerman PJ. Transcription of the FMR1 gene in individuals with fragile X syndrome. Am J Med Genet. 2000;97:195-203.

3. Wittenberger MD, Hagerman RJ, Sherman SL, McConkie-Rosell A, Welt CK, Rebar RW, Corrigan EC, Simpson JL, Nelson LM. The FMR1 premutation and reproduction. Fertil Steril. 2007;87:456-65.

4. Hagerman RJ, Hagerman PJ. Testing for fragile $X$ gene mutations throughout the life span. JAMA. 2008;300:2419-21.

5. Brouwer JR, Willemsen R, Oostra BA. The FMR1 gene and fragile $X$ associated tremor/ataxia syndrome. Am J Med Genet B Neuropsychiatr Genet. 2009;150B:782-98.

6. Sherman SL. Premature ovarian failure in the fragile $X$ syndrome. Am J Med Genet. 2000:97:189-94

7. Allingham-Hawkins DJ, Babul-Hirji R, Chitayat D, Holden JJ, Yang KT, Lee C, Hudson R, Gorwill H, Nolin SL, Glicksman A, et al. Fragile X premutation is a significant risk factor for premature ovarian failure: the International Collaborative POF in Fragile X study-preliminary data. Am J Med Genet. 1999:83:322-5

8. Hunter JE, Epstein MP, Tinker SW, Charen KH, Sherman SL. Fragile Xassociated primary ovarian insufficiency: evidence for additional genetic contributions to severity. Genet Epidemiol. 2008;32:553-9.

9. Fu YH, Kuhl DP, Pizzuti A, Pieretti M, Sutcliffe JS, Richards S, Verkerk AJ, Holden JJ, Fenwick Jr RG, Warren ST, et al. Variation of the CGG repeat at the fragile $X$ site results in genetic instability: resolution of the Sherman paradox. Cell. 1991;67:1047-58.

10. Gleicher N, Weghofer A, Barad DH. Ovarian reserve determinations suggest new function of FMR1 (fragile $X$ gene) in regulating ovarian ageing. Reprod Biomed Online. 2010;20:768-75.

11. Gleicher N, Weghofer A, Lee $H$, Barad DH. Association of FMR1 genotypes with in vitro fertilization (IVF) outcomes based on ethnicity/race. PLoS One. 2011;6:e18781.

12. Gleicher N, Weghofer A, Lee $\mathbb{H}$, Barad DH. FMR1 genotype with autoimmunity-associated polycystic ovary-like phenotype and decreased pregnancy chance. PLoS One. 2010;5:e15303.

13. Gleicher N, Weghofer A, Kim A, Barad DH. The impact in older women of ovarian FMR1 genotypes and sub-genotypes on ovarian reserve. PLoS One. 2012;7:e33638

14. Gleicher N, Yu Y, Himaya E, Barad DH, Weghofer A, Wu YG, Albertini DF, Wang VQ, Kushnir VA. Early decline in functional ovarian reserve in young women with low (CGG) FMR1 gene alleles. Transl Res. 2015;166(5):502-7.

15. Hoffman GE, Le WW, Entezam A, Otsuka N, Tong ZB, Nelson L, Flaws JA, McDonald JH, Jafar S, Usdin K. Ovarian abnormalities in a mouse model of fragile X primary ovarian insufficiency. J Histochem Cytochem. 2012;60:439-56.

16. Voorhuis M, Onland-Moret NC, Fauser BC, van Amstel HK P, van der Schouw YT, Broekmans FJ. The association of CGG repeats in the FMR1 gene and timing of natural menopause. Hum Reprod. 2013;28:496-501.

17. Gleicher N, Kushnir VA, Weghofer A, Barad DH. How the FMR1 gene became relevant to female fertility and reproductive medicine. Front Genet. 2014;5:284.

18. Yang $Y, X u$ S, Xia L, Wang J, Wen $S$, Jin $P$, Chen D. The bantam microRNA is associated with drosophila fragile $X$ mental retardation protein and regulates the fate of germline stem cells. PLoS Genet. 2009;5:e1000444.

19. Megosh HB, Cox DN, Campbell C, Lin H. The role of PIWI and the miRNA machinery in Drosophila germline determination. Curr Biol. 2006;16:1884-94.

20. Tabolacci E, Neri G. Epigenetic modifications of the FMR1 gene. Methods Mol Biol. 2013;1010:141-53.

21. Boumil RM, Lee JT. Forty years of decoding the silence in X-chromosome inactivation. Hum Mol Genet. 2001;10:2225-32.
22. Lyon MF. Gene action in the X-chromosome of the mouse (Mus musculus L.). Nature. 1961;190:372-3.

23. Cotton AM, Lam L, Affleck JG, Wilson IM, Penaherrera MS, McFadden DE, Kobor MS, Lam WL, Robinson WP, Brown CJ. Chromosome-wide DNA methylation analysis predicts human tissue-specific $X$ inactivation. Hum Genet. 2011;130:187-201.

24. Brown CJ. Skewed X-chromosome inactivation: cause or consequence? J Natl Cancer Inst. 1999;91:304-5.

25. Lucchesi JC, Kelly WG, Panning B. Chromatin remodeling in dosage compensation. Annu Rev Genet. 2005;39:615-51.

26. Barad DH, Weghofer A, Gleicher N. Utility of age-specific serum antiMullerian hormone concentrations. Reprod Biomed Online. 2011;22:284-91.

27. Chen L, Hadd AG, Sah S, Houghton JF, Filipovic-Sadic S, Zhang W, Hagerman PJ, Tassone F, Latham GJ. High-resolution methylation polymerase chain reaction for fragile $X$ analysis: evidence for novel FMR1 methylation patterns undetected in Southern blot analyses. Genet Med. 2011;13:528-38.

28. Benjamini Y, Hochberg Y. Controlling the False Discovery Rate: A Practical and Powerful Approach to Multiple Testing. J R Stat Soc Ser B Methodol. 1995;57:289-300.

29. Gleicher N, Barad DH. The FMR1 gene as regulator of ovarian recruitment and ovarian reserve. Obstet Gynecol Surv. 2010;65:523-30.

30. Seifer DB, Baker VL, Leader B. Age-specific serum anti-Mullerian hormone values for 17,120 women presenting to fertility centers within the United States. Fertil Steril. 2011;95:747-50.

31. Iliodromiti S, Kelsey TW, Anderson RA, Nelson SM. Can anti-Mullerian hormone predict the diagnosis of polycystic ovary syndrome? A systematic review and meta-analysis of extracted data. J Clin Endocrinol Metabol. 2013;98:3332-40.

32. Gleicher N, Weghofer A, Oktay K, Barad D. Relevance of triple CGG repeats in the FMR1 gene to ovarian reserve. Reprod Biomed Online. 2009;19:385-90.

33. Chow JC, Yen Z, Ziesche SM, Brown CJ. Silencing of the mammalian X chromosome. Annu Rev Genomics Hum Genet. 2005;6:69-92.

34. Ng K, Pullirsch D, Leeb M, Wutz A. Xist and the order of silencing. EMBO Rep. 2007:8:34-9.

35. Goto T, Monk M. Regulation of X-chromosome inactivation in development in mice and humans. Microbiol Mol Biol Rev. 1998;62:362-78.

36. Weghofer A, Tea MK, Barad DH, Kim A, Singer CF, Wagner K, Gleicher N. BRCA1/2 mutations appear embryo-lethal unless rescued by low (CGG $n<$ 26) FMR1 sub-genotypes: explanation for the "BRCA paradox"? PLoS One. 2012;7:e44753.

37. Laitman Y, Ries-Levavi L, Berkensdadt M, Korach J, Perri T, Pras E, Friedman E. FMR1 CGG allele length in Israeli BRCA1/BRCA2 mutation carriers and the general population display distinct distribution patterns. Genet Res. 2014;96:e11.

38. de Vries BB, Wiegers AM, Smits AP, Mohkamsing S, Duivenvoorden HJ, Fryns JP, Curfs LM, Halley DJ, Oostra BA, van den Ouweland AM, Niermeijer MF. Mental status of females with an FMR1 gene full mutation. Am J Hum Gene. 1996:58:1025-32.

39. Garcia-Alegria E, Ibanez B, Minguez M, Poch M, Valiente A, Sanz-Parra A, Martinez-Bouzas C, Beristain E, Tejada MI. Analysis of FMR1 gene expression in female premutation carriers using robust segmented linear regression models. RNA. 2007;13:756-62.

40. Amos-Landgraf JM, Cottle A, Plenge RM, Friez M, Schwartz CE, Longshore J, Willard HF. X chromosome-inactivation patterns of 1,005 phenotypically unaffected females. Am J Hum Gene. 2006;79:493-9.

41. Rodriguez-Revenga L, Madrigal I, Badenas C, Xuncla M, Jimenez L, Mila M. Premature ovarian failure and fragile $X$ female premutation carriers: no evidence for a skewed X-chromosome inactivation pattern. Menopause. 2009;16:944-9.

42. Rousseau F, Heitz D, Oberle I, Mandel JL. Selection in blood cells from female carriers of the fragile $X$ syndrome: inverse correlation between age and proportion of active $X$ chromosomes carrying the full mutation. J Med Genet. 1991;28:830-6.

43. Maddalena A, Richards CS, McGinniss MJ, Brothman A, Desnick RJ, Grier RE, Hirsch B, Jacky P, McDowell GA, Popovich B, et al. Technical standards and guidelines for fragile $X$ : the first of a series of diseasespecific supplements to the Standards and Guidelines for Clinical Genetics Laboratories of the American College of Medical Genetics. Quality Assurance Subcommittee of the Laboratory Practice Committee. Genet Med. 2001;3:200-5. 
44. Oberle I, Rousseau F, Heitz D, Kretz C, Devys D, Hanauer A, Boue J, Bertheas MF, Mandel JL. Instability of a 550-base pair DNA segment and abnormal methylation in fragile X syndrome. Science. 1991;252:1097-102.

45. Spath MA, Nillesen WN, Smits AP, Feuth TB, Braat DD, van Kessel AG, Yntema HG. X chromosome inactivation does not define the development of premature ovarian failure in fragile $X$ premutation carriers. Am J Med Genet A. 2010;152A:387-93.

46. Gleicher N, Kim A, Barad DH, Shohat-Tal A, Lazzaroni E, Michaeli T, Lee HJ, Kushnir VA, Weghofer A. FMR1-dependent variability of ovarian aging patterns is already apparent in young oocyte donors. Reprod Biol Endocrinol. 2013;11:80

Submit your next manuscript to BioMed Central and we will help you at every step:

- We accept pre-submission inquiries

- Our selector tool helps you to find the most relevant journal

- We provide round the clock customer support

- Convenient online submission

- Thorough peer review

- Inclusion in PubMed and all major indexing services

- Maximum visibility for your research

Submit your manuscript at www.biomedcentral.com/submit
Biomed Central 